\title{
MODIFIED NONLINEAR DYNAMICAL EQUATIONS FOR RELATIONSHIP IN MARRIAGES
}

Talabi Adetoro Temitope; Chukwuma Victor Uzodinma and Odunaike Rasaki. Kolawole Department of Physics, Olabisi Onabanjo University, Ago-Iwoye, Nigeria

Corresponding Author's E-mail: talabi.adetoro@oouagoiwoye.edu.ng

\section{ABSTRACT}

Love-stories are characterized by temporal fluctuations, experiment in the area of relationship are difficult to design but mathematical models play vital role in studying the dynamics of relationship living together as ideal couple or fragile couple and the divorcee A modified nonlinear coupled dynamic model was used to predict and interpret the feature of the union of different individuals and it is adapted to local environment where the data collection is carried out. We also investigated several measures affecting marriages, different challenges in marriage were considered by the use of questionnaires, analyzed and the results were applied as parameters in the model. In other words, only few of the behaviour of the couples to each other are taken into account while the rest of the answers were kept frozen, results were used to confirm if the behaviour of certain number of individuals observed in real life can be explained through the answers provided by individuals in the survey whic was included in the theory. Numerical simulations are also presented to show the effectiveness of the survey results.

Keywords: Non-linear, Mathematical model, relationship, marriages.

Accepted Date: 23 May 2018

\section{INTRODUCTION}

The study of dynamical system that is, a system which consists of a set of possible state togethe with a rule that determines the present state in term of the past states has advanced tremendously many decades ago, making a big impact on science an technology (Liao and Ran, 2007). The dynamics of different systems both linear and nonlinear had been studied widely and interpreted with the aid of phase plots to show the behaviour of the system. It has come to our thought that no one, no matter our profession sexual tension and or other related thing. However, about approximaly $80 \%$ of in the ro child bearing. The focus of this research work is to study fragile relationship between two individuals that is, husband and wife using a modified nonlinear differential equation called Couple dynamics which models marriage with the aim of identifying chaotic marriage as fragile couple. Marriage refers to mutual interaction between two or more individuals usually male and female as in the case for Nigeria. One of the earliest efforts at modeling marital relationships was by a group of researchers and mathematicians who teamed up to create a mathematical model that predicts future of marriages using a set of first order differentia equations. Strogatz described a model calle minimal model on love whose aim was to teach harmonic oscillation phenomena in the classroom (Sprott, 2004; Cheriff and Barley, 2011), but his model was unrealistic because he did not consider appeal of the couple in his differential equation. Apea the couple in his dereserion. Appeal can becoutes position e.c. Splon, (2001) in potential, social position e.t.c. Sprott (2001) in his paper presente to the Chaos and Complex system seminar in Madison, Wisconsin (2001) disagreed with Strogatz work and described a model of love and happiness which he referred to as Love model for Romeo and Juliet .Marriage can be viewed from different perspectives; but this work will focus on the Socio-psychology and Physics perspective. 


\section{Socio-psychologist perspective}

Marriage exists to bring man and woman together as husband and wife to be father and mother to any children their union produces. Kefalas, Furstenberg, Carr and Napolitano (2011) identified two groups of marriage: marriage naturalist and marriage planners. Marriage naturalists are largely from rural area and are eager to get married while marriage planners delay their entry into marriage as a response to the haphazard transition to adulthood, they are based in city. The age at which people marry has risen therefore making the proportion of people getting married to fall (Cherlin, 2004; Ventura and Bachrach, 2000) because of the fear of divorce and this increases the growth in the proportion of children born to unmarried mothers. Stranger-Ross, Collins and Stern, 2005) in their work identified three different decisions of young adults on marriage i.e. reciprocity, dependence and autonomy. Reciprocity was practiced between the period of 1900-1950, dependence between (1950-1970) and autonomy (1970-2000). Human believe that love is the main foundation of marriage, according to (D'Vera, 2013) love has the highest percentage as the important reason to marry, the percentage for each reasons are Love 93\%, Making A Life Long Commitment $87 \%$, Companionship $81 \%$, Having Children 59\%, Financial Stability $31 \%$.Marriage is an important goal, though it may not be the top priority but having a successful marriage is one of the most important things.

\section{Physics perspective}

We will notice that when Newton invented calculus. It put science on a mathematical foundation and Physics took off. The Psychologists has lagged behind using mathematics and with this, they are not exposed to models. This work will extract key elements into a model to make it predictive and interpretive. There are no general laws of marriage relationship as there are for Physics but, Newton's second law can be used to categorize relationship. It states that a body will continue in its state of rest or a uniform motion until an external force is being applied on it. This is to say that, couple that has no influence by external forces can be called 'ideal couple' while the other way round is called 'fragile couple'. Also, law of thermodynamics for sentimental relationship states that there is tendency for initial feeling of one another to fade away hence effort is required to sustain relationship as love is not enough (Jose-Manuel, 2010). Closeness between couple can be viewed from two aspects in this work. Firstly from semiconductor Physics and secondly from modeling with the aid of differential equation. Looking at the latter, marriages could start off happily but over time there could be challenges which can be referred to as "CHAOS thereby left a wide forbidden gap between the conduction band (husband) and the valence (wife). To appreciate this discussion in the light of physics, an analogy can be drawn between marital relationships an energy bands of solids. Lets recall that in the energ band, there is forbidden gap which is wide in an insulator (no feelings) and in metal there is no forbidde gap (existence of love), this shows that for love to exist between the individual there must occur a therma excitation of electrons from the valence band to the conduction band, therefore husband can be attracted to his wife when his body is able to charge at sighting his wife, this is related to fundamental law of actio between charges which states that "like charges repe and unlike charges attract". John Gottman, a clinical Psychologist and mathematicians James Murray an Kristin Swanson (2001) predicted the future of marriages by introducing a model but before developin the model, the team organized a conversation between couples and each partner was scored during the conversation using a strict set of criteria. The scores were then used to develop a model to predict an interpret future of marriages. Differential equation was used to generate a phase plot which predict how likely the relationship is to survive. Marriage dynamic therefore provides the foundation for a scientific theory of marital relations which necessitated the present study to give postulation(s) of possible stability in marriage such that the chaos therein could be controlled.

\section{METHODOLOGY}

\section{Data presentation}

Survey (using questionnaire) was conducted among young and old married men and women with the aid of
questionnaires. The couples invited to fill the questionnaires were the fragile couples and the idea couples. The survey papers used comprise of three sections. The sul number of samples taken of three three hundred but one hundred questionnaires were used for the analysis while others were invalid Lagos states were the target areas of the study. This is shown in table 1 .

MODEL DESCRIPTION- Couple dynamic equations attention in scientific community with its andysis contributing to a vast list of research in this field. The model used is the nonlinear coupled with two differential equations which were a modified from the existing model as in equations (1.0) and (1.1)

$$
\begin{aligned}
& \frac{d X_{1}}{d t}=-a_{1} x_{1}(t)+b_{1} x_{2}\left(1-e x_{2}^{2}\right)+\left(x_{2}^{2}-x_{1}^{2}\right)+f(t) \ldots \ldots \ldots \\
& \frac{d X_{2}}{d t}=-a_{2} x_{2}(t)+b_{2} x_{1}\left(1-e x_{1}^{2}\right)+\left(x_{2}^{2}-x_{1}^{2}\right)+f(t) \ldots
\end{aligned}
$$

The challenges considered as parameters are:

$$
\begin{aligned}
a_{1} & =\text { maltreatment }, & a_{2} & =\text { loneliness }, \\
b_{2} & =\text { phone calls, } & f(t) & =\text { periodic forcing, }
\end{aligned}
$$

$x_{1}=$ measure of orderliness/disorderliness in individual 1

$x_{2}=$ measure of orderliness/disorderliness in individual 2

\section{Numerical results}

The data collected from questionnaires were analyzed The sample size was determined according to specified model. Demographic information in respect to the relationship length of participants were recorded but participants were inconsistent in the amount of demographic information provided. Not all questionnaires provided the necessary information for for the andys. The furlysis resuls for some pick for the ansysis. The alysis resuls for some of

In order to investigate the dynamics of the model

overtime, the systems of equations were integrated using the fourth order Runge-Kutta methods in programming language to solve systems (3.1) and (3.2). Few of the

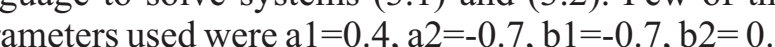
and $\mathrm{e}=0.4$. Figures $4 \mathrm{a}$ and $4 \mathrm{c}$ are the chaotic plots of those that agreed with the questions while figures $4 \mathrm{e}$ and $\mathrm{g}$ for those that disagreed and the respective time serie plots were also shown. Those that agreed with question showed more chaotic behaviour than those that efrective The num

\section{Data analysis}

Table 1: Survey results of 100 sampled couples Questions
always maltreat and

beat $\mathrm{m}$

Undecided
Disagreed Agreed Invalid Total 1 (83 answers) 2(2 answers) $3(15$ answers $) \quad 0 \quad 100$

$\begin{array}{llllll}\text { Often my spouse ignores me } & 1 \text { ( } 67 \text { answers }) & 2(8 \text { answers }) & 3 \text { (24 answers) } & 1 & 100\end{array}$

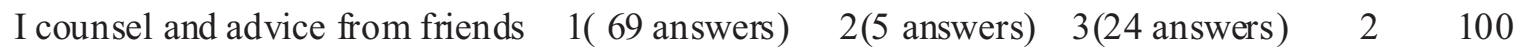
I pick up my spouse phone when

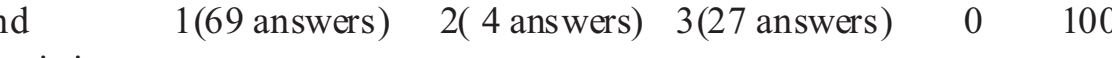
My parent/parent-in-law is in 1 (82 answers $) \quad 2(2$ answers $) \quad 3(14$ answers $) \quad 2$ 
The mean rating for each item was calculated by multiplying the number of answers in a category by is rating value obtaining a sum and dividing by the total number of answers for that item. To calculate the mean for the first item: for example, my spouse always maltreat and beat me.

Multiply answers by value

Undecided $=83(83 * 1)$

Disagree $=4(2 * 2)$

Agree $=\quad 45(5 * 3)$

Sum. $\quad 83+8+45=132$

Divide by N: $\frac{32}{100}=1.32$ ( mean rating)

\section{Graphical representation of data}

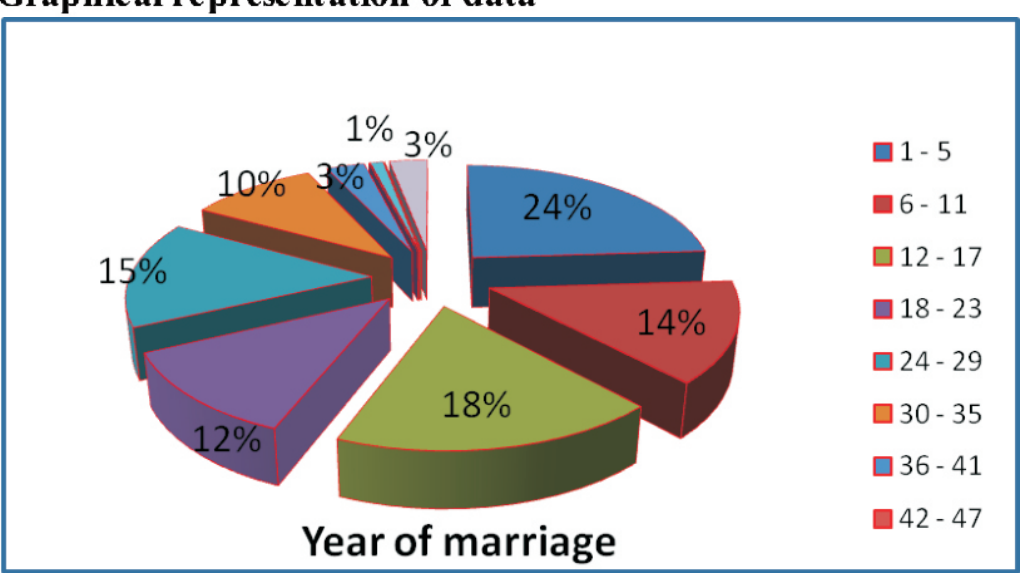

Figure 1 pie-chart showing year of marriage.

Fig. 1 depicts the purpose to observe the time trend as how couples introduce maturity into their marriageand the thewat they handle their problems

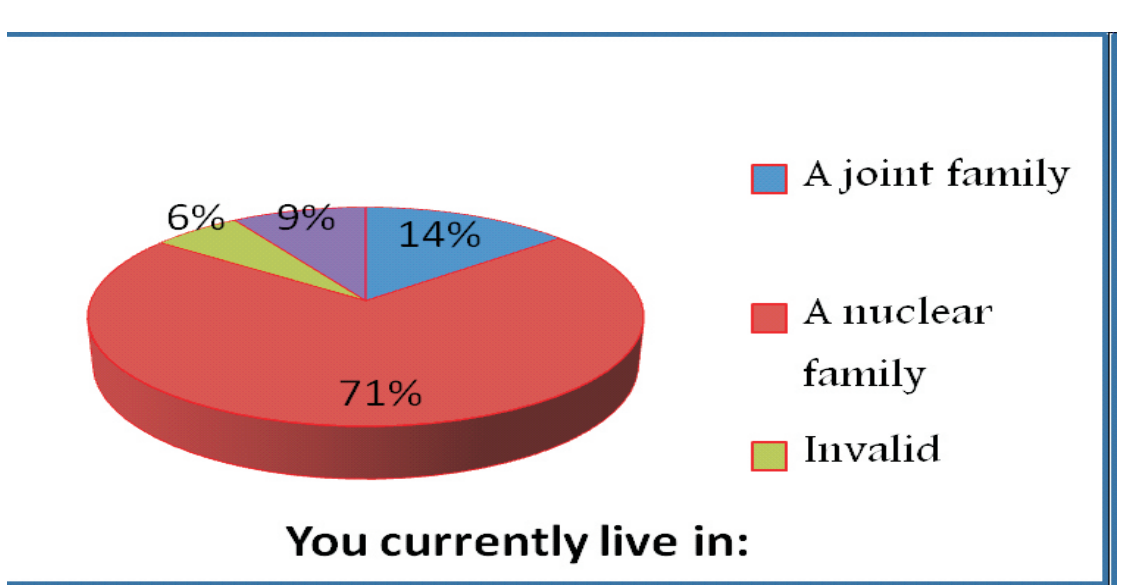

Figure 2: The pie-chart depicting the current living mode. The question address the nature living mode of couples as depicted in Fig. $2 b$ namely a nuclear family, a joint family, others

It also shows the current day living style of couple's life whether or not they like to live with their elders or they prefer me, my spouse and children.

$$
\mathrm{j}_{\mathrm{SN}}
$$

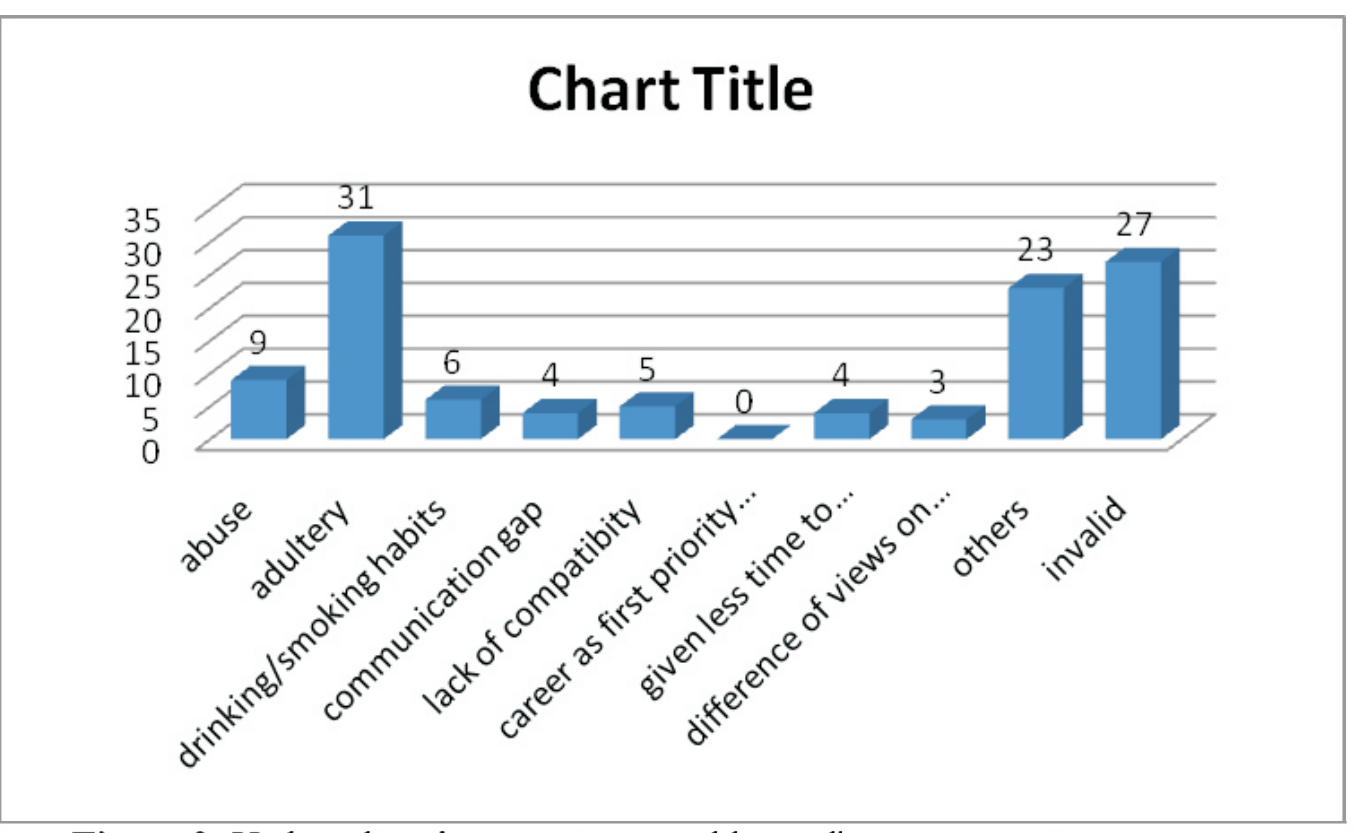

Figure 3: Under what circumstances would you divorce your spouse

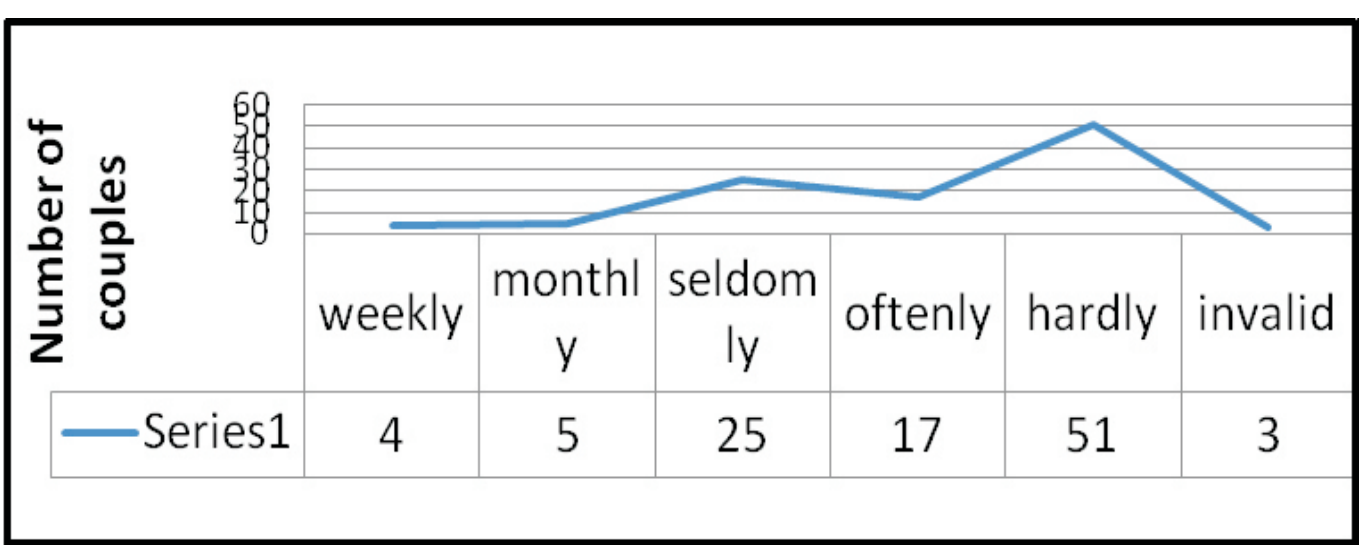

Figure 4: This is to know how often cou ples quarrel at home

Numerical Results

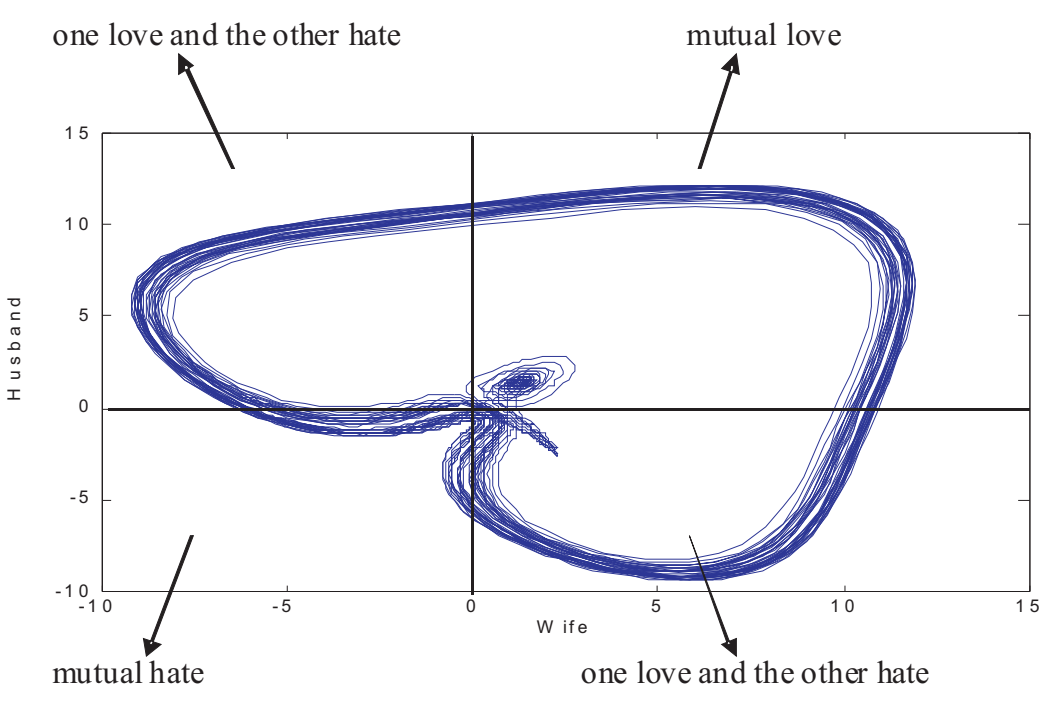

Figure 5 Chaotic behaviour of the couples that agreed with the questions being asked. 


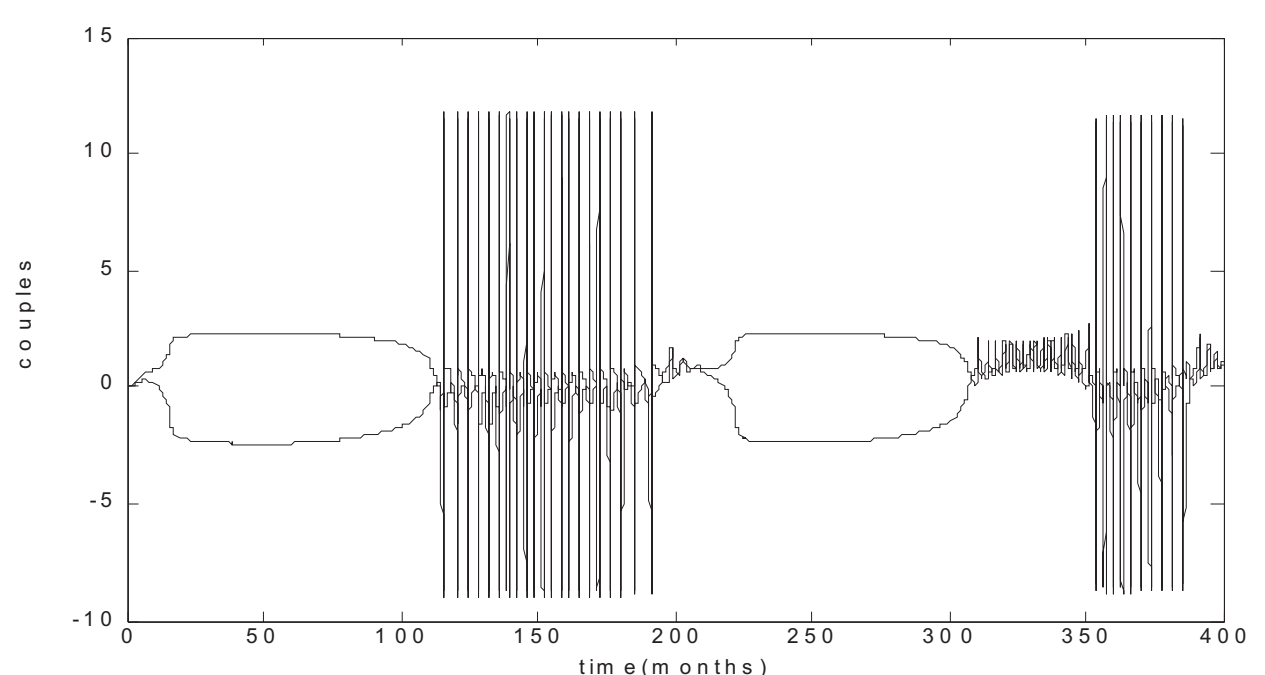

Figure 6: Chaotic behaviour of couple's dynamics with a periodic forcing from eq. 1.0 and 1.

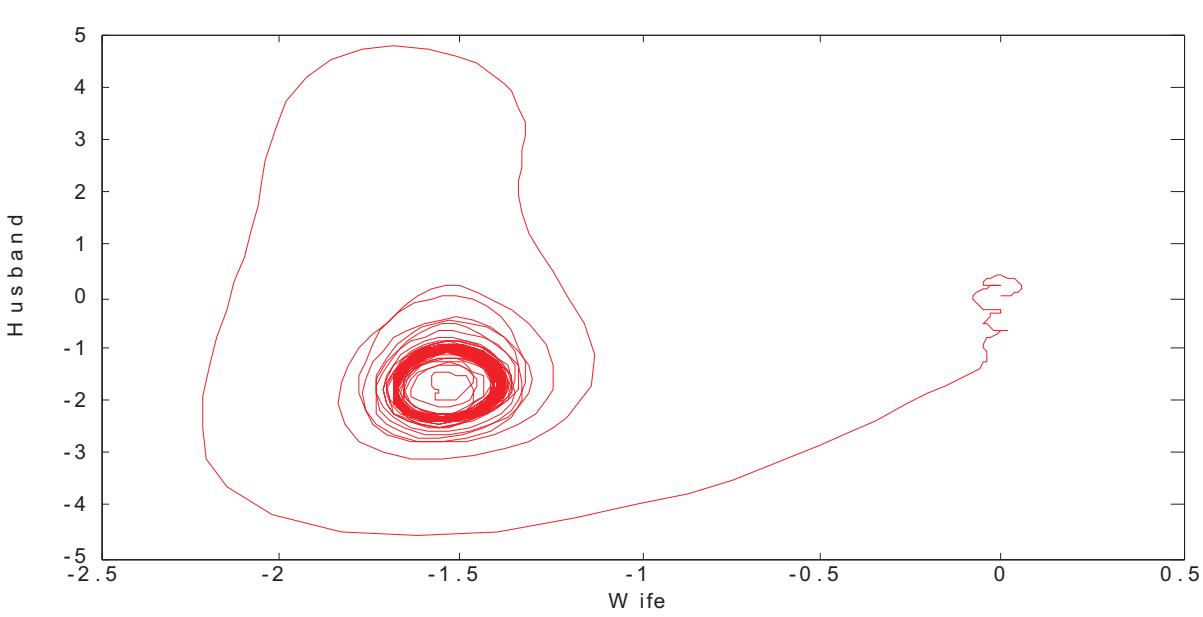

Figure 7: Chaotic behaviour of the couples that a greed to the questions, showing the chaoticity more to mutual hate axis

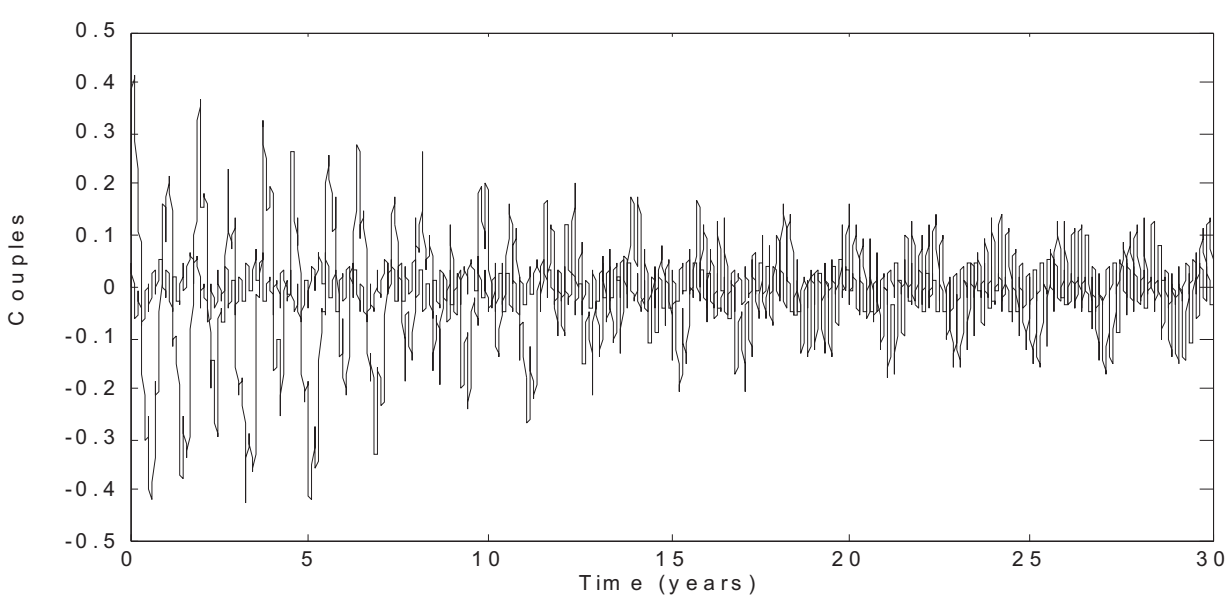

Figure 8: Chaotic behaviour of couples dyna mics with a periodic forcing from eq. 8.1 and 8.2

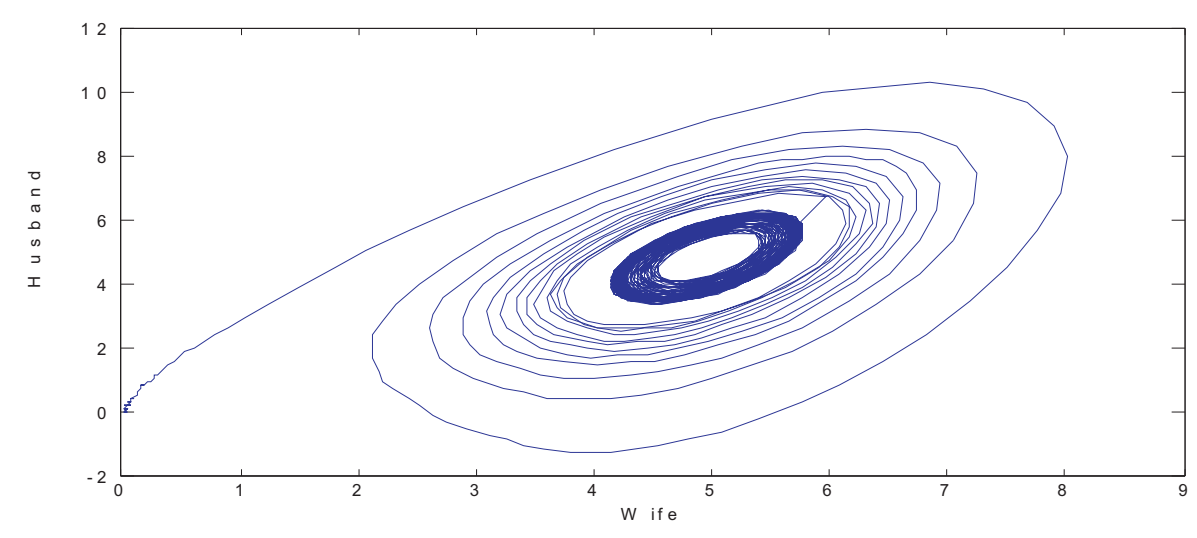

Figure 9: Chaotic behaviour of the couples that disagreed with the questions being asked base on the parameters used.

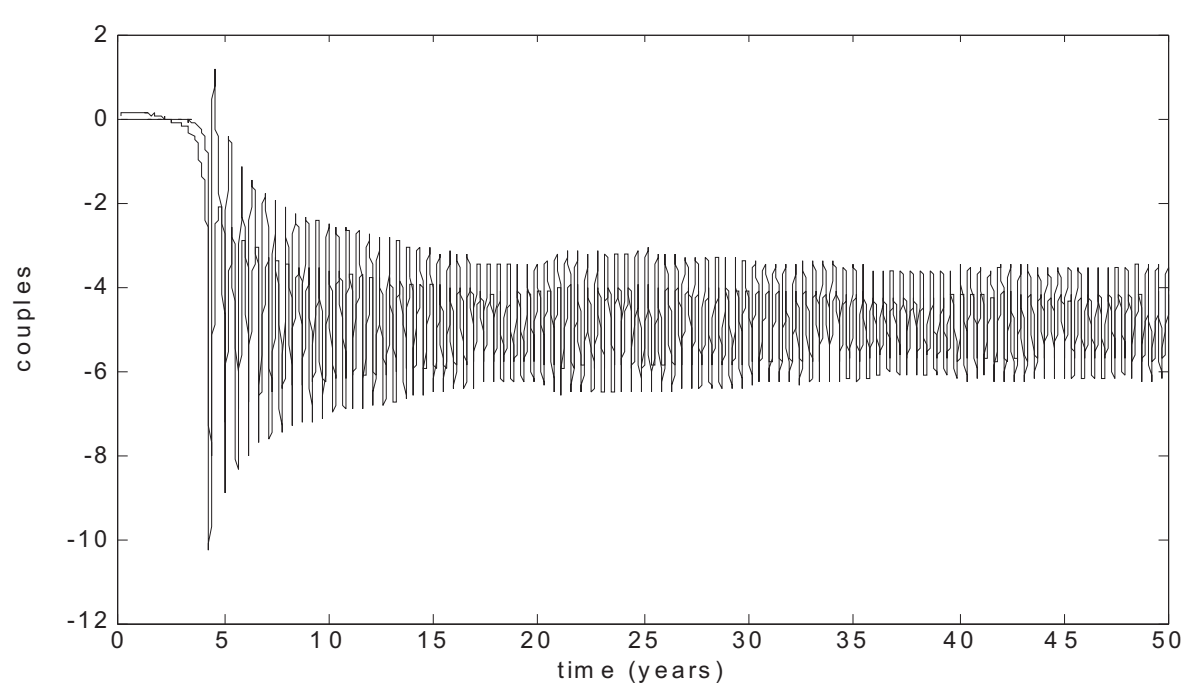

Figure 10: Chaotic evolution of the couples that disagreed to the questions

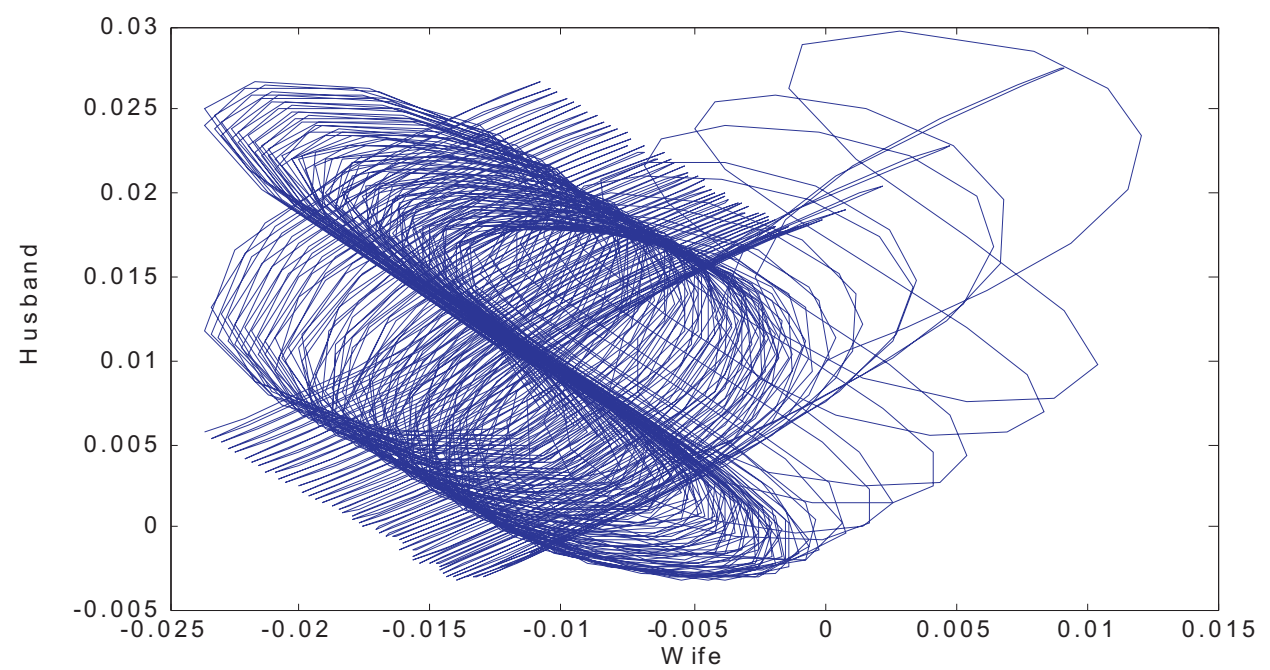

Figure 11: Strange attractor from the nonlinear dynamical systems ( mean rating)

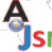

P-ISSN 2536-6904 African Journal of Science \& Nature Vol. 7, 50-57 (2018) 


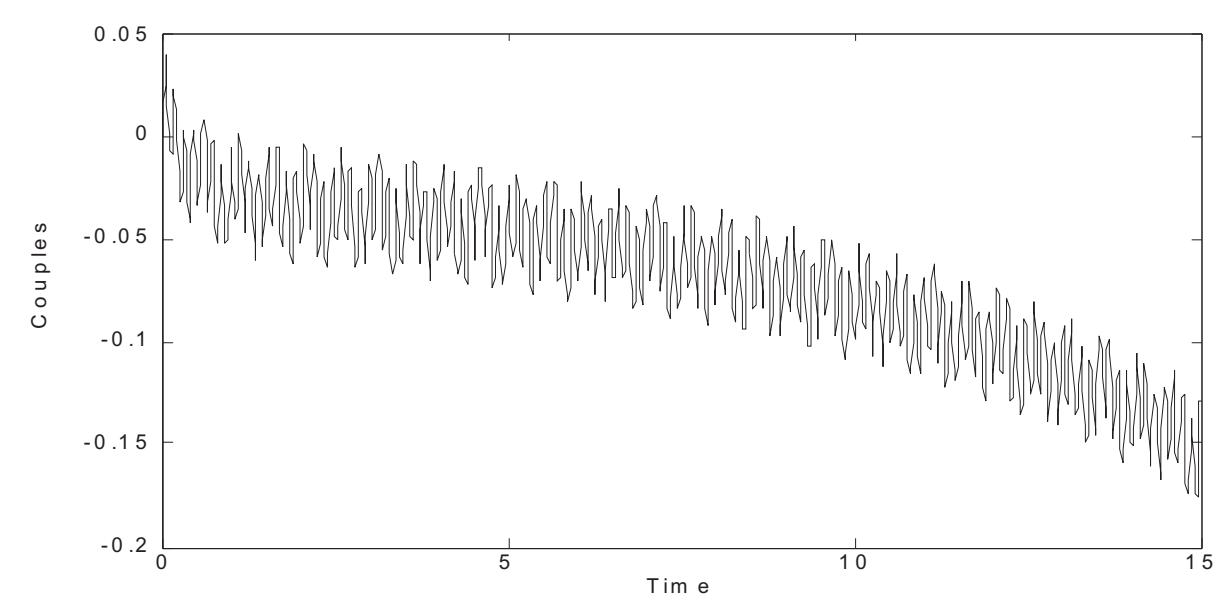

Figure 12: Chaotic behaviour of couples dynamics with a periodic forcing.

\section{Conclusion}

In the present work, we modify the linear love dynamic model by introducing nonlinear terms. The model was used to interpret the future of most marriages, the effectiveness and appli

More so, this research was carried out to establish the reason behind the increasing divorce rate among young couples these days. However, the work also focuses on analyzing data with the aid of questionnaires, interprets the result with the aid of phase plots, time series and charts. Finding solutions to the problems young couples are facing is a problen current research work is attempting to un-ravel to allow reasonable stability to enhance marriage so that the socio-economic growth and development in the nation can be improved upon.

\section{References}

Cherif, A., \& Barley, K., (2011). Stochastic nonlinear dynamics of interpersonal and romantic relationships. Applied Mathematics and Computation, 217(13):6273-6281. doi:10.1016/j.amc. 2010.12.117.

Cherlin, A. (2004). The deinstutionalization of marriage. Journal of Marriage and Family, 66(4): 848-861. doi:10.1111/j.0022-2445.2004.00058.x

D'Vera, C. (2013). Pew research center, social and demographic trends.

Gottman, J. M., Swanson, C. C., \& Murray, J. D. (2005). The Mathermatics of marital conflict: Dynamic mathematical nonlinear modeling of newlywed marital interaction. The MIT Press.

ose-Manuel R. (2010). A mathematical model of sentimental dynamics accounting for marital dissolution. PloS ONE 5 (3), e9881. doi: 10.1371 journal. pone. 0009881

Kefalas, M. J., Furstenberg, F. F., Carr, P. J., \& Napolitano, L. (2011). Marriage is more than being together: The meaning of marriage for young adults. Journal of Family Issues, 32(7): 845-875. doi 10.1177/0192513X10397277.

Liao, X., \& Ran, J. (2007). Hopf bifurcation in love dynamical models with nonlinear couples and time delays. Chaos, Solitons and Fractals 31 (4) 853-865. doi:10.1016/j.chaos.2005.10.037

Sprott, J.C. (2001). Dynamics of love and Happiness, Chaos and Complex Systems Seminar in Madison, Wisconsin 2001.

Sprott, J. C. (2004). Dynamical Models of Love. Nonlinear Dynamics Psychology and Life Sciences, 8(3): 303-313.

Stanger-Ross, J., Collins, C., \& Stern, M. (2005) Falling far from the tree: Transitions to adulthood and the social history of Twentieth Century America. Social Science History, 29 (29) : 625648. doi:10.1017/S014555320001333

Ventura, S. J., \& Bachrach, C. A. (2000). Non marital childbearing in the United States, 1940-1999. National Vital Statistics Reports, 48 (16), Washington, DC: 